\title{
THE MEDIATING ROLE OF ROMANTIC RELATIONSHIPS BETWEEN OPTIMISM AND DEPRESSION IN EMERGING ADULTS
}

\author{
Elena Cattelino, Federica Graziano \\ University of Aosta Valley, Italy \\ E-mail: e.cattelino@univda.it, federicagra@tiscali.it
}

\author{
Emanuela Calandri \\ University of Turin, Italy \\ E-mail: emanuela.calandri@unito.it
}

\begin{abstract}
The existing literature showed that higher depression is linked to less optimism and to poor quality of romantic relationship, but studies considering the role of both optimism and romantic relationship on depression among emerging adults are lacking. The aims of the study were: 1) to describe the quality of romantic relationship, optimism and depression in a group of Italian emerging adults; 2) to examine the relation between optimism and depression; 3) to investigate the possible mediating role of quality of romantic relationship on the relation between optimism and depression. The study involved 228 emerging adults (59\% girls), aged from 18 to 22 (mean age $=19.5$, standard deviation=1.2). Optimism was assessed through the Life Orientation Test-Revised (LOT-R; Scheier et al., 1994), depression through the Center for Epidemiologic Studies Short Depression Scale (CES-D 10; Andresen et al., 1994) and quality of romantic relationships through the Romance Qualities Scale (RQS; Ponti et al., 2010). Main results showed a partial mediating effect of quality of romantic relationship between optimism and depression: less optimistic emerging adults reported higher depression, but the effect of lack of optimism was mediated by a good relationship with the partner. Implications for theory and practice were discussed.
\end{abstract}

Key words: depression, emerging adults, mediation, optimism, romantic relationship.

\section{Introduction}

Depression is recognized as one of the major mental health problems around the world. In Italy, in line with other European countries, the lifetime prevalence for major depression is $11.2 \%$ (14.9\% among women and 7.2\% among men) (De Girolamo et al., 2006). For this type of mental disturbance, transitions in the lifespan represent moments of increased vulnerability. In recent years scholars' attention has gradually increased for one of these transition periods, namely emerging adulthood.

The concept of emerging adulthood was introduced by Arnett (2000) to identify the life period from 18 to 25 years. This period is distinct from the preceding adolescence and the following adulthood and it is characterized by more autonomy than adolescence, but less commitment than adulthood. Salient developmental tasks of this period concern work and romantic relationships (Roisman et al., 2004) and the main characteristic is often a prolonged exploration of different possibilities, before taking a complete adult role. This period is typical of industrialized Western 
societies, where scholarization is often prolonged, the entry in the labour market is delayed and it is often difficult because of the widespread economic crisis (Arnett, 2000; 2007a). During emerging adulthood people are likely to postpone important life decisions, like living alone, establishing stable romantic relationships, living with a partner/getting married or having children.

Characteristics of emerging adulthood have been above all investigated in North American and North European cultures, while studies involving Mediterranean countries, like Italy, are less numerous (Piumatti et al., 2013). Typical features of emerging adulthood, namely long scholarization, difficulties in finding a job and prolonged permanence in the family, seem to be particularly pronounced in Italy. People come of age when they are 18 years old, by the age of 19 they generally conclude high school and between 20 and 25 many of them attend University, while the others often look for a job or are employed in temporary jobs. The rate of unemployment in Italy is one of the highest among European countries and also the mean age at which people leave parental home (around 30 years) is one of the highest in Europe (EU youth report, 2012). As a consequence, emerging adulthood, especially in Italy, seems to be a mixed-up condition, with elements typical of adolescence, like prolonged studies and the influence of the family (Scabini, Marta and Lanz, 2006) and others typical of adulthood, like commitment in job and romantic relationships, but generally with exploration and without stable decisions.

In existing studies emerging adulthood is generally portrayed like a period in which individuals experiment increasing psychological well-being and on average self-esteem increases and depression decreases (Galambos, Barker and Krahn, 2006). Notwithstanding, some emerging adults might encounter difficulties in coping with developmental tasks of this period and high variance in mental health might be observed: in particular, the developmental path of a minority of emerging adults could be characterized by an increase in depression (Arnett, 2007b), above all among girls (Hankin and Abramson, 2001). Studies highlight that precocious age at onset in depressive symptoms is associated with subsequent depression into adult life and in particular young adults with depression are at high risk of developing other psychological symptoms and poorer psychological and social functioning during adulthood (Smith and Blackwood, 2004). For this reason, it is particularly important to analyse the variables that can protect against depression in this age of life.

Among the studies on factors influencing depression during emerging adulthood, some have focused on individual variables, like personality traits (Smith and Blackwood, 2004), self-esteem (Orth, Robins and Roberts, 2008) and coping strategies (Carbonell, Reinherz and Beardslee, 2005), while less attention has been given to optimism. Optimism is an individual variable that refers to generalized favourable expectancies for the future (Carver, Scheier and Lopez, 2003). Literature has for a long time debated whether optimism is a stable individual characteristic, namely a trait (Scheier and Carver, 1985), or where it is a modifiable condition, namely a state, changing in relation to the context and life situations (Seligman, 1975). Independently of the construct definition (trait versus state), optimism has proved to be positively linked to psychological well-being (Carver, Scheier and Segerstrom, 2010) and inversely related to depression. Notwithstanding the role of optimism on depression has been studied among adolescents (Sumer et al., 2009), older adults (Achat et al., 2000) and in clinical samples (Hirsch, Conner, Duberstein, 2007; Karlsson et al., 2011), while studies among emerging adults are lacking.

Among contextual factors influencing depression during emerging adulthood, attention has been traditionally given to work condition (Galambos, Barker and Krahn, 2006) and family relationships (Reinherz et al., 2003; Milevsky, 2005), while more recent research pointed out the role of romantic relationships too. As stated before, the increasing involvement in a stable relationship with a partner is one of the developmental tasks of emerging adulthood. The relationship with a partner represents a context for the adult identity achievement (Furman and Schaffer, 2003; Lanz and Tagliabue, 2007; McNamara Barry et al., 2009) and many developmental functions fulfilled in adolescence by family and friends (e.g. independence, affection, identity redefinition), are fulfilled by the partner during emerging adulthood. Also the salient dimensions of romantic relationship change from adolescence to emerging adulthood: the needs of companionship, affection and emotional support are gradually integrated by greater intimacy, commitment, and faithfulness (Seiffge-Krenke, 2003). For their relevance in emerging adulthood, romantic relationships should 
be considered as factors influencing depression. In particular not romantic relationships per se, but their good quality has proved to be linked to lower depression (Whitton and Kuryluk, 2012) and to higher psychological well-being and happiness above and beyond the effect of personality factors (Demir, 2008).

In light of the outlined framework, in the present study the attention was focused on depression in a group of Italian emerging adults and two factors that might have a protective role against depression, namely optimism and quality of romantic relationships were considered. In line with Burke and colleagues (2000) and Chiesi and colleagues (2013), optimism was investigated as generalized favourable expectancies for the future that is dispositional optimism. As previously said, studies concerning emerging adults in Italy are scarce and research on the role of optimism on depression during emerging adulthood is lacking. Diverse studies investigated the role of romantic relationships on depression at this age, but there are no studies considering together the role of optimism and quality of romantic relationships on depression.

In particular a possible mediating role of quality of romantic relationships on the relation between optimism and depression was investigated. A previous study pointed out the mediating role of parental support between optimism and depression in adolescence (Sumer et al., 2009), while there are no studies, especially in the Italian context, focusing on the mediating role of romantic relationship between optimism and depression in emerging adults.

It is known that more optimistic people also refer higher satisfaction for social relationships (Brisette, Scheier and Carver, 2002) and these in turn are protective with respect to depression (Jones, 2013). It would be therefore interesting to investigate the possible mediating role of romantic relationship, both in a theoretical and in a practical perspective. On one hand, moving from the assumption that the individual development takes always place in a context under the influence of different variables (Silbereisen, Eyferth and Rudinger, 1986; Ford and Lerner, 1992), the focus on mediating processes is likely to better describe the complexity of phenomena under investigation. In particular the study of mediation processes would allow reaching a better understanding of the influence of optimism on depression. On the other hand, if quality of romantic relationships mediates the link between an individual belief, like optimism, and depression, quality of romantic relationships might be considered as a potential protective factor to take into account and on which to perform specific education interventions.

Based on what has been said, the goals of the study were the following:

1. To describe depression, optimism and quality of romantic relationship in a group of Italian emerging adults (18 to 22 year-olds) taking into account gender differences;

2. To examine the relation between optimism and depression;

3. To investigate the possible mediating role of quality of romantic relationship on the relation between optimism and depression.

Due to the explorative nature of the study, no specific hypotheses were formulated concerning the first aim, even though, on the basis of previous research, higher depression was expected among girls. With regard to the second aim, higher depression was expected to be related to lower optimism. Finally, concerning the third aim, the negative relationship between optimism and depression was expected to decrease after introducing the quality of romantic relationship, thus suggesting a partial mediating role of this variable.

\section{Methodology of Research}

\section{Sample of Research}

A non-representative convenience sample was used for this study. The group of participants was selected from a larger group of 422 emerging adults: only people who referred to be at present involved in a romantic relationship were selected for the present study. The final sample included 228 emerging adults $(\mathrm{N}=135,59 \%$ girls), aged from 18 to 22 (mean age $=19.5$, standard deviation $=1.2)$. The majority of participants $(\mathrm{N}=124 ; 55 \%)$ were high school students, $85(37 \%)$ attended 
university while the remaining $19(8 \%)$ completed high school and were looking for a job. Most participants $(\mathrm{N}=141 ; 62 \%)$ reported to have been involved in the current romantic relationship for more than one year, $29(13 \%)$ for a period ranging from six months to one year and the remaining $58(25 \%)$ for less than six months. The mean score of depression was 9.1 (standard deviation = 5.8) thus the sample was below the critical cut-off (10) for significant depressive symptoms.

\section{Instrument and Procedures}

Participants were requested to fill in an anonymous self-report questionnaire that included sociodemographic variables, variables about romantic and friends relationships, psychological wellbeing and depression. In this study depression, optimism and the quality of romantic relationship were considered.

Depression was assessed through the Center for Epidemiologic Studies Short Depression Scale (CES-D 10; Andresen et al., 1994). It comprises 10 items on a 4-points Likert response format, from 0 (rarely or none of the time) to 3 (most or all of the time). (Cronbach's alpha $=0.82$; range 0-30; a cut off score of 10 or higher indicates the presence of significant depressive symptoms).

Optimism was evaluated through the Life Orientation test-Revised (LOT-R; Scheier et al., 1994; Chiesi et al., 2013). It comprises 10 items (3 positive, 3 negative and 4 fillers) with a 5-points Likert response format ranging from 0 (strongly disagree) to 4 (strongly agree). (Cronbach's alpha $=0.72$; range $0-24$ ).

Quality of romantic relationship was evaluated through the Romance Qualities Scale (RQS; Ponti et al., 2010). It comprises 22 items describing different situations typical of romantic relationship (e.g. My partner and I spend all our free time together; My partner helps me when I am having trouble with something). People expressed their agreement on a 5-points Likert scale ranging from 1 (absolutely false) to 5 (absolutely true). Participants were asked to respond with reference to their relationship with current partner (Cronbach's alpha $=0.86$; range 22-110).

High school students completed the questionnaire in the classrooms, during school hours, without teachers present and immediately returned it to researchers. The other participants were contacted directly by researchers, then filled in the questionnaire at home and returned it in a closed envelope in a mailing box at University. $93 \%$ of delivered questionnaires were returned. Formal consent from participants was obtained prior to data collection, in accordance with Italian law and the ethical code of the Professional Psychologists Association.

\section{Data Analysis}

Statistical analyses were performed by using SPSS (Statistical Package for Social Science), version 20. The mean differences in depression, optimism and quality of romantic relationship of gender were investigated through Student's t-test for independent samples.

To investigate the relation between optimism and depression and the mediating role of quality of romantic relationship the approach suggested by Baron and Kenny (1986) was followed. In a first regression quality of romantic relationships (mediator) was regressed on optimism (predictor); then in a hierarchical multiple regression, depression (criterion) was regressed in the first step on optimism (predictor) and in the second step on both optimism (predictor) and quality of romantic relationships (mediator). A partial mediation effect occurs if optimism predicts both quality of romantic relationship and depression and if the relation between optimism and depression decreases after entering into regression quality of romantic relationship. In all regressions, gender was entered as control variable.

\section{Results of Research}

Table 1 shows the results about gender differences in levels of depression, optimism and quality of romantic relationship: girls reported higher depression and better quality of romantic relationships than boys (see Table 1), while no gender differences emerged for optimism. 
Table 1. Means and Standard Deviations (SD) of depression, optimism and quality of romantic relationship by gender.

\begin{tabular}{|c|c|c|c|c|c|c|c|c|c|}
\hline & \multicolumn{3}{|c|}{ Boys } & \multicolumn{3}{|c|}{ Girls } & \multirow{2}{*}{$\mathrm{t}$} & \multirow{2}{*}{ df } & \multirow{2}{*}{$p$} \\
\hline & $N$ & M & SD & $\mathrm{N}$ & M & SD & & & \\
\hline Depression & 91 & 7.9 & 5.8 & 130 & 9.9 & 5.8 & 2.64 & 219 & 0.009 \\
\hline Optimism & 93 & 14.3 & 4.0 & 132 & 13.3 & 4.4 & -1.81 & 223 & 0.071 \\
\hline $\begin{array}{l}\text { Quality of romantic } \\
\text { relationship }\end{array}$ & 91 & 87.6 & 10.4 & 133 & 92.2 & 8.7 & 3.53 & 222 & 0.001 \\
\hline
\end{tabular}

Results of the regression analyses are shown in Table 2 and Table 3. Optimism significantly predicts quality of romantic relationships $(\beta=0.259)$ : in particular higher quality of romantic relationship was linked to higher optimism after taking into account the role of gender (Table 2).

Table 2. Regression analysis (optimism on quality of romantic relationship).

\begin{tabular}{cccccc}
\hline \multicolumn{5}{c}{ Quality of romantic relationship } \\
\hline Predictor & $\beta(\mathbf{p})$ & $\mathbf{F}(\mathrm{df})$ & $\mathbf{p}$ & $\mathbf{R} 2$ & $\Delta \mathbf{R 2}$ \\
\hline Gender & $\begin{array}{c}-0.239 \\
(0.000)\end{array}$ & $\begin{array}{c}13.25 \\
(1,219)\end{array}$ & 0.000 & 0.053 & 0.053 \\
& $\begin{array}{c}-0.271 \\
(0.000)\end{array}$ & $\begin{array}{c}15.29 \\
(2,218)\end{array}$ & 0.000 & 0.115 & 0.062 \\
Gender & $\begin{array}{c}0.259 \\
(0.001)\end{array}$ & & & & \\
\hline
\end{tabular}

Results of hierarchical regression (table 3 ) showed that optimism significantly predicted depression $(\beta=-0.484)$ after controlling for gender: in particular higher levels of depression were linked to lower levels of optimism. After entering the quality of romantic relationship in the second step, the effect of optimism on depression decreased $(\beta=-0.402)$ and quality of romantic relationship significantly predicted depression $(\beta=-0.311)$ : in particular higher levels of depression were linked to lower quality of romantic relationship. The final model accounted for $34 \%$ of the variance in depression. The mediation model is shown in Figure 1.

Table 3. Regression analysis (optimism and quality of romantic relationship on depression).

\begin{tabular}{ccccccc}
\hline \multicolumn{7}{c}{ Depression } \\
\hline Step & Predictors & $\boldsymbol{\beta}(\mathbf{p})$ & $\mathbf{F}(\mathrm{df})$ & $\mathbf{p}$ & $\mathbf{R} 2$ & $\Delta \mathbf{R 2}$ \\
\hline 1 & Gender & $-0.187(0.006)$ & $\begin{array}{c}7.77 \\
(1,215)\end{array}$ & 0.006 & 0.030 & 0.030 \\
\hline \multirow{2}{*}{2} & Gender & $-0.130(0.029)$ & $\begin{array}{c}38.74 \\
(2,214)\end{array}$ & 0.000 & 0.259 & 0.229 \\
& Optimism & $-0.484(0.000)$ & & & & \\
\hline \multirow{4}{*}{3} & Gender & $-0.214(0.000)$ & 38.25 & 0.000 & 0.341 & 0.082 \\
& $\begin{array}{c}\text { Optimism } \\
\text { Quality of romantic } \\
\text { relationship }\end{array}$ & $-0.402(0.000)$ & & & & \\
& $-0.311(0.000)$ & & & & \\
\hline
\end{tabular}




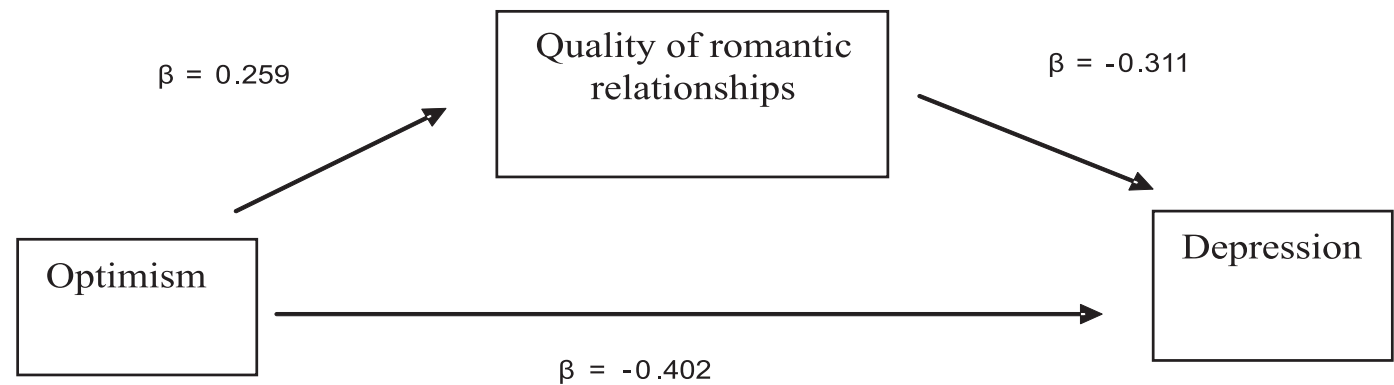

Figure 1. Mediation model.

\section{Discussion}

The study aimed at describing depression, optimism and quality of romantic relationship in a group of Italian emerging adults, taking into account gender differences and investigating relationships among the three examined variables. In particular the mediating role of quality of romantic relationship on the relation between optimism and depression was investigated.

Concerning the first aim (describing depression, optimism and quality of romantic relationship), levels of optimism and quality of romantic relationship resulted to be quite high, while depression levels were under the critical cut-off for the presence of significant depressive symptoms, thus confirming typical characteristics of a non-clinical sample. Concerning gender, these findings pointed out some differences: in particular, as expected, the girls reported greater depression, but also better quality of romantic relationship. Other studies found higher depression for girls, not only for emerging adults, but also for adolescents and adults (Hankin and Abramson, 2001). With regard to gender differences in perceived quality of romantic relationship, these results are in line with other studies suggesting that girls perceive greater intimacy in romantic relationships and globally better evaluate the relationship with their partner (Montgomery, 2005).

With regard to the second aim (to examine the relation between optimism and depression), the results confirmed, as expected, that higher depression was related to lower optimism. The negative relationship between depression and optimism has received little attention in this phase of the life-span and the results of the present study seem to confirm what already observed among populations of different ages, in particular adolescents (Sumer et al., 2009) and older adults (Achat et al., 2000): as a whole, having favourable expectancies for the future seems to be an individual variable that protects against depression.

Finally, a possible mediating effect of quality of romantic relationships between optimism and depression was examined. As hypothesized, the results stressed that the role of dispositional optimism on depression was mediated by the quality of romantic relationships. The relationship between optimism and depression did not disappear after taking into account the quality of romantic relationship, but it decreased, thus suggesting a partial mediation effect. In other words, more optimistic emerging adults are likely to be more satisfied of their romantic relationship and this in turn contrasts depression. This result adds to existing knowledge in confirming the protective role of good romantic relationships during emerging adulthood, above and beyond the effect of individual variables (Demir, 2008).

The study has some limitations. First of all, the sample of the present study only included 18 to 22 year-olds, while also 23 to 25 year-old people should be considered according to the classical age range of emerging adulthood. Secondly, the small sample size does not allow for a generalizability of results and a larger sample would be useful. Furthermore, it would be important to replicate these findings in different cultural contexts. In fact, as it was pointed out, in Italy the transition to adulthood is longer than in other European countries. Thirdly, the cross-sectional design of the study prevents from a causal interpretation of these results. As previously said, while it is plausible that more optimistic people perceive a better quality of romantic relationship, it is also plausible that the direction of the effects is the opposite or, more likely, both constructs influence each other 
in a bidirectional way. For these reasons, future research should investigate relationships among the considered variables in a longitudinal design, also including multiple sources of information and qualitative instruments to deepen knowledge about the role of romantic relationships during emerging adulthood.

\section{Conclusions}

Emerging adulthood is a transition period during the life-span representing for the majority of individuals a moment of positive change experienced with enthusiasm and positivity. Notwithstanding some emerging adults experiment worries and lack of confidence in the future and this negative experience is likely to lead to depressive symptoms. The prevalence of depression is strongly increasing in Western countries, like Italy, first of all in relation to a strong and widespread social and economic crisis. As pointed out by the World Health Organization (2013), for the next twenty years the economic consequences of health losses related to mental disorders will be very large for Western countries. In light of these considerations, the analysis of factors likely to contrast depression is crucial, above all for young people.

In this regard, among individual variables, the present study confirmed the role of optimism: having generalized favourable expectancies is particularly meaningful above all during this period of the life-span in which the confidence for the future and the commitment on life projects become more concrete and overcome dreams typical of adolescence. The confidence in the future realization of personal life projects is central for emerging adults, especially during the current historical moment, characterized by an economic and social crisis in which pessimism is widespread and transmitted especially by older adults. This attitude could promote not only a disengagement of emerging adults from their life projects, but also an increase in depression among young people representing the future of society. In line with the literature on resilience, it is important to defend optimism and confidence among young people in the future, in spite of difficult life conditions.

The findings of the present study show that optimism can contrast, depression both directly and indirectly, through its effect on the quality of romantic relationship. The mediating role of romantic relationships has both theoretical and practical relevance.

With regard to the theoretical aspects, the attention on mediating processes better describes the complexity of developmental processes, characterized by continuous and multidirectional interactions between individual and contexts. Findings confirmed the relevance of intimate relationships in promoting individual well-being and reducing psychological uneasiness. Starting from this result, it would be interesting to investigate more in depth some underlying processes, like the relationship between optimism and quality of romantic relationship. In fact, a negative quality of romantic relation might be due to a more general negative inclination towards events and life; on the other hand, a lower quality in romantic relationship might be at the same time cause and effect of the negative inclination developed by the individual in previous social experiences with parents and peers.

Concerning applicative implications, results stressed that in groups at risk for depression a preventive intervention is possible, focusing not only on individual variables, but also on contextual factors, like relationship with the partner, if present.

\section{References}

Achat, H., Kawachi, I., Spiro, A., DeMolles, D. A., \& Sparrow, D. (2000). Optimism and depression as predictors of physical and mental health functioning: the normative aging study. Annals of Behavioral Medicine, 22 (2), 127-130. DOI: 10.1007/BF02895776.

Andresen, E. M., Malmgren, J. A., Carter, W. B., \& Patrick, D. L. (1994). Screening for depression in well older adults: evaluation of a short form of the CES-D (Center for Epidemiologic Studies Depression Scale). American Journal of Preventive Medicine, 10, 77-84. 
Arnett, J. J. (2000). Emerging adulthood: A theory of development from the late teens through the twenties. American Psychologist, 55, 469-480. DOI: 10.1037/0003-066X.55.5.469.

Arnett, J. J. (2007a). Emerging Adulthood: What Is It, and What Is It Good For? Child Development Perspectives, 1 (2), 68-73. DOI: 10.1111/j.1750-8606.2007.00016.x.

Arnett, J. J. (2007b). Suffering, Selfish, Slackers? Myths and Reality About Emerging Adults. Journal of Youth and Adolescence, 36, 23-29. DOI: 10.1007/s10964-006-9157-z

Baron, R. M., \& Kenny, D. A. (1986). The moderator-mediator variable distinction in social psychological research: Conceptual, strategic and statistical considerations. Journal of Personality and Social Psychology, 51, 1173-1182. DOI: 10.1037/0022-3514.51.6.1173.

Brisette, I., Scheier, M. F., \& Carver, C. S. (2002). The role of optimism in social network development, coping, and psychological adjustment during a life transition. Journal of Personality and Social Psychology, 82, 102-111. DOI: 10.1037/0022-3514.82.1.102.

Burke, K. L., Joyner, A. B., Czech, D. R., \& Wilson, M. J. (2000). An investigation of concurrent validity between two optimism/pessimism questionnaires: The life orientation test-revised and the optimism/pessimism scale. Journal of Current Psychology, 19 (2), 129-136. DOI: 10.1007/s12144-000-1009-5.

Carbonell, D. M., Reinherz, H. Z., \& Beardslee, W. R. (2005). Adaptation and Coping in Childhood and Adolescence for those at Risk for Depression in Emerging Adulthood. Child and Adolescent Social Work Journal, 22 (5-6), 395-416. DOI: 10.1007/s10560-005-0019-4.

Carver, C. S., Scheier, M., \& Lopez, S. J. (Ed). (2003). Positive psychological assessment: A handbook of models and measures. Washington: APA.

Carver, C. S., Scheier, M. F., \& Segerstrom, S. C. (2010). Optimism. Clinical Psychology Review, 30 (7), 879889. DOI: 10.1016/j.cpr.2010.01.006.

Chiesi, F., Galli, S., Primi, C., Innocenti Borgi, P., \& Bonacchi, A. (2013). The accuracy of the Life Orientation Test-Revised (LOT-R) in measuring dispositional optimism: Evidence from item response theory analyses. Journal of Personality Assessment, 1-7. DOI: 10.1080/00223891.2013.781029.

De Girolamo, G., Polidori, G., Morosini, P., Scarpino, V., Reda, V., Serra, G., Mazzi, F., Alonso, J., Vilagut, G., Visonà, G., Falsirollo, F., Rossi, A., \& Warner, R. (2006). Prevalence of common mental disorders in Italy. Results from the European Study of the Epidemiology of Mental Disorders (ESEMeD). Social Psychiatry and Psychiatric Epidemiology, 41, 853-61. DOI: 10.1007/s00127-006-0097-4.

Demir, M. (2008). Sweetheart, you really make me happy: Romantic relationship quality and personality as predictors of happiness among emerging adults. Journal of Happiness Studies, 9, 257-277. DOI: 10.1007/ s10902-007-9051-8.

European Union (2012). EU youth report 2012. Luxembourg: Publications Office of the European Union.

Ford, D. H., \& Lerner, R. M. (1992). Developmental systems theory: an integrative approach. London: Sage Publications.

Furman, W., \& Schaffer, L. (2003). The role of romantic relationships in adolescent development. In P. Florsheim (Ed.), Adolescent romantic relations and sexual behavior: Theory, research, and practical implications (pp. 3-22). Mahwah, NJ: Lawrence Erlbaum Associates.

Furman, W., \& Winkles, J. K. (2010). Predicting romantic involvement, relationship cognitions, and relationship qualities from physical appearance, perceived norms, and relational styles regarding friends and parents. Journal of Adolescence, 33, 827-836. DOI: 10.1016/j.adolescence.2010.07.004.

Galambos, N. L., Barker, E. T., \& Krahn, H. J. (2006). Depression, self-esteem, and anger in emerging adulthood: Seven-year trajectories. Developmental Psychology, 42 (2), 350-365. DOI: 10.1037/0012-1649 .42 .2 .350 .

Hankin, B. L., \& Abramson, L. Y. (2001). Development of gender differences in depression: An elaborated cognitive vulnerability-transactional stress theory. Psychological Bulletin, 127 (6), 773-796. DOI: 10.1037/0033-2909.127.6.773.

Hirsch, J. K., Conner, K. R., \& Duberstein, P. R. (2007). Optimism and suicide ideation among young adult college students. Archives of Suicide Research, 11 (2), 177-85. DOI: 10.1080/13811110701249988. 
Jones, A. (2013). The association between depression and family, romantic, and peer support in adults. Honors Theses. Paper, 268.

Karlsson, H., Kronstrom, K., Nabi, H., Oksanen, T., Salo, P., Virtanen, M., Suominen, S., Kivimaki, M., \& Vahtera, J. (2011). Low level of optimism predicts initiation of psychotherapy for depression: Results from the Finnish public sector study. Psychotherapy \& Psychosomatics, 80 (4), 238-244. DOI: $10.1159 / 000323613$.

Lanz, M., \& Tagliabue, S. (2007). Do I really need someone in order to become an adult? Romantic relationships during emerging adulthood in Italy. Journal of Adolescent Research, 22, 531-549. DOI: 10.1177/0743558407306713.

McNamara Barry, C., Madsen, S. D., Nelson, L. J., Carroll, J. S., \& Badger, S. (2009). Friendship and romantic relationship qualities in emerging adulthood: Differential associations with identity development and achieved adulthood criteria. Journal of Adult Development, 16 (4), 209-222.

Milevsky, A. (2005). Compensatory patterns of sibling support in emerging adulthood: Variations in loneliness, self-esteem, depression and life satisfaction. Journal of Social and Personal Relationships, 22 (6), 743755. DOI: $10.1177 / 0265407505056447$.

Montgomery, M. J. (2005). Psychosocial intimacy and identity: From early adolescence to emerging adulthood. Journal of Adolescent Research, 20, 346-374. DOI: 10.1177/0743558404273118.

Orth, U., Robins, R. W., \& Roberts, B. W. (2008). Low self-esteem prospectively predicts depression in adolescence and young adulthood. Journal of Personality and Social Psychology, 95 (3), 695-708. DOI: 10.1037/0022-3514.95.3.695

Piumatti, G., Pipitone, L., Di Vita, A. M., Latina, D., \& Rabaglietti, E. (2013). Transition to adulthood across Italy: A comparison between northern and southern Italian young adults Journal of Adult Development, 20 (2), 1-12. DOI: 10.1007/s10804-013-9174-6

Ponti, L., Guarnieri, S., Smorti, A., \& Tani, F. (2010). A measure for the study of friendship and romantic relationship quality from adolescence to early-adulthood. The Open Psychology Journal, 3, 76-87.

Reinherz, H. Z., Paradis, A. D., Giaconia, R. M., Stashwick, C. K., \& Fitzmaurice, G. (2003). Childhood and adolescent predictors of major depression in the transition to adulthood. American Journal of Psychiatry, 160, 2141-2147.

Roisman, G. I., Masten, A. S., Coatsworth, J. D., \& Tellegan, A. (2004). Salient and emerging developmental tasks in the transition to adulthood. Child Development, 75, 123-133. DOI: 10.1111/j.1467-8624 .2004.00658.x.

Scabini, E., Marta, E., \& Lanz, M. (2006). Transition to adulthood and family relations: An intergenerational perspective. Hove, New York: Psychology Press.

Scheier, M. F., \& Carver, C. S. (1985). Optimism, coping, and health: assessment and implications of generalized outcome expectancies. Health Psychology, 4 (3), 219-247. DOI: 10.1037/0278-6133.4.3.219.

Scheier, M.F., Carver, C.S., \& Bridges, M.W. (1994). Distinguishing optimism from neuroticism (and trait anxiety, self-mastery, and self-esteem): a reevaluation of the Life Orientation Test. Journal of Personality and Social Psychology, 67 (6), 1063-1078. DOI: 10.1037/0022-3514.67.6.1063

Seiffge-Krenke, I. (2003). Testing theories of romantic development from adolescence to young adulthood: Evidence of a developmental sequence. International Journal of Behavioral Development, 27, 519-531. DOI: $10.1080 / 01650250344000145$.

Seligman, M. E. P. (1975). Helplessness: On depression, development, and death. San Francisco: Freeman.

Silbereisen, R. K., Eyferth, K., \& Rudinger, G. (1986). Development as action in context. Berlin: SpringerVerlag.

Smith, D. J., \& Blackwood, D. H. R. (2004). Depression in young adults. Advances in Psychiatric Treatment, 10, 4-12. DOI: 10.1192/apt.10.1.4.

Sumer, M., Giannotta, F., Settanni, M., \& Ciairano, S. (2009). Parental support as mediator between optimism and depression in early adolescents. Journal of Psychology and Counseling, 1 (8), 139-146.

Whitton, S. W., \& Kuryluk, A. D. (2012). Relationship satisfaction and depressive symptoms in emerging adults: 
cross-sectional associations and moderating effects of relationship characteristics. Journal of Family Psychology, 26 (2), 226-235. DOI: 10.1037/a0027267.

WHO - World Health Organization (2013). Mental health action plan 2013-2020. ISBN 9789241506021.

Advised by Michel Born, Service of Psychology of Delinquency, Liège, Belgium of Human and Social Sciences, Strada dei Cappuccini 2/A, 11100 Aosta, Italy. E-mail: e.cattelino@univda.it

E-mail: federicagra@tiscali.it 